\title{
Limites da expressão "veículos automotores" para fins de incidência do IPVA: as embarcações e aeronaves
}

\author{
Limits of expression "automotive vehicles" for purposes of incidence of ipva: vessels and \\ aircraft
}

\author{
Pérola Toneti de Oliveira ${ }^{1}$ \\ Suélen S. Cordeiro da Silva ${ }^{2}$ \\ Thatiana Freitas Tonzar ${ }^{3}$
}

\begin{abstract}
Resumo
Apresentou- se um estudo acerca da problemática doutrinária e jurisprudencial existente em relação ao complemento "veículo automotor" contido no critério material da hipótese de incidência tributária do IPVA, acerca dos limites de tal expressão em relação às embarcações e às aeronaves. Para tanto, analisou-se, sinteticamente, o critério material, bem como cada um de seus elementos. Apresentaram-se as teses doutrinárias e jurisprudenciais favoráveis e contrárias à incidência do imposto sobre esses veículos (embarcações e aeronaves) . Verificou-se que as teses contrárias à incidência ganham maior repercussão perante os Estados, uma vez que o Supremo Tribunal Federal firmou precedente ao entender pela não incidência do IPVA nesses casos. Concluiu-se acerca da possibilidade de Lei Complementar uniformizar tal questão conflitante.
\end{abstract}

Palavras Chave: IPVA; Critério material; Embarcações; Aeronaves.

\begin{abstract}
It was expost a study about doctrinal and jurisprudential problematics that exists in the complement of "automotive vehicle" contained in the material criterion of the hypothesis of tax incidence of IPVA, this study is bound to the limits of such expression in relation to vessels and aircraft. To this end it was analyzed, summarized, the material criterion, as well as each of its elements. It was Introducted the doctrinal and jurisprudential arguments for and against the incidence of tax on these vehicles (vessels and aircraft). It was found that the arguments against the incidence earn greater impact in the States since the Supreme Court precedent in finding signed by the non IPVA incidence of such cases. As conclusion, it was understood that is possible a Complementary Law standardizes such conflicting subject.
\end{abstract}

Keywords: IPVA; Criterion material; Vessels; Aircraft.

\footnotetext{
${ }^{1}$ Graduada do curso de Direito da Universidade Estadual de Londrina

${ }^{2}$ Graduada do curso de Direito da Universidade Estadual de Londrina

${ }^{3}$ Graduada do curso de Direito da Universidade Estadual de Londrina
} 


\section{Introdução}

O presente artigo cuida do imposto previsto no art.155, III da Constituição Federal, sobre a propriedade de veículos automotores (IPVA), especificamente quanto à problemática doutrinária e jurisprudencial existente em relação ao complemento "veículo automotor" contido no critério material da hipótese de incidência tributária do imposto, acerca dos limites de tal expressão em relação às embarcações e as aeronaves.

Primeiramente, antes de adentrar aos vários questionamentos a respeito da incidência do imposto sobre tais veículos, faz-se necessária a apresentação da hipótese tributária da exação, sobretudo no que tange ao seu critério material, constituído em "ser proprietário de veículo automotor", detalhando cada componente do complemento que acompanha o verbo "ser" do critério material.

Após, o artigo propõe-se a analisar imparcialmente a autorização conferida pelo texto constitucional para a incidência do imposto, a partir dos conceitos previstos no Código de Trânsito Brasileiro, Regulamento de Tráfego M arítimo e Código Brasileiro de Aeronáutica, e pela apresentação de teses doutrinárias favoráveis a tributação, como a da ampla abrangência do conceito "veículo automotor", e a inexistência de lei nacional que delimite a expressão, e teses contrárias, como as que defendem a existência de invasão dos Estados em matéria de competência exclusiva da União, a vedação da aplicação de analogia para fins de incidência e a de ausência de registro estadual e municipal desses veículos junto ao Estado.

\section{Critério material da hipótese de incidência do IPVA}

O tema proposto para o presente trabalho atinge diretamente o critério material da hipótese de incidência tributária do Imposto sobre a Propriedade de Veículos Automotores IPVA, portanto, necessário se faz a análise genérica acerca do referido critério, bem como dos conceitos de seus elementos, para, então, adentrar-se especificamente no assunto acerca do que se pode entender por veículo automotor, passível de tributação por esse imposto.

A Constituição Federal de 1988 estipulou em seu art. 155, III, a competência dos Estados e do Distrito Federal para instituir e cobrar o IPVA, ratificando a previsão trazida 


\section{Limites da expressão "veículos automotores" para fins de incidência do IPVA: as embarcações e aeronaves}

pela Emenda Constitucional № 27 de 1985, a qual, sob a égide da Constituição de 1967 introduziu em nosso ordenamento o IPVA, que a partir de então, passou a ser corretamente denominado de 'imposto' (M ARTINS, 2007, p. 747).

0 próprio dispositivo constitucional prescreve o critério material do referido imposto, desse modo observa-se que o sinal de riqueza que enseja a exação consiste, I."em ser proprietário” (verbo) II. “de veículo automotor” (complemento).

Nesse sentido, as legislações ordinárias estaduais estão limitadas a legislar acerca da tributação sobre a propriedade desse tipo de veículo, acabando por reproduzir o texto constitucional.

Como exemplo, eis o que dispõe a Lei Estadual do Paraná, de n. 14.260/03, que trata sobre a regulamentação acerca da instituição de cobrança do IPVA:

\section{Capítulo I \\ DO FATO GERADOR \\ (...)}

Art. 20 - O IPVA tem como fato gerador a propriedade de veículo automotor e será devido anualmente.

Desse modo, para a correta identificação do Critério Material, é necessário entender 0 que vem a ser cada um desses elementos.

A propriedade, de acordo com o que dispõe o art. 1228 do Código Civil, é a faculdade de usar, gozar e dispor da coisa, bem como de reavê-la do poder de quem injustamente a possua ou detenha.

Diante de sua definição, é importante ressalvar que a propriedade do veículo não surge com a sua fabricação, pois o veículo não serve ao fabricante com os fins específicos de locomoção. Nesse caso, enquanto o veículo encontrar-se com o fabricante, importador, vendedor, é tratado como mercadoria, ensejando a incidência de outros tributos próprios de tais fases.

Assim, até a alienação do veículo automotor para o consumidor final, seja ele pessoa física ou jurídica, fica impossibilitada a cobrança do tributo em comento, uma vez que sua incidência, enquanto mercadoria, ensejaria um ônus injustificado à mesma, acabando por encarecê-la, o que acabaria por afetar a livre iniciativa e a viabilização da atividade econômica, institutos constitucionalmente protegidos - arts. 1 ํㅡ e 170 §1ํㅡ, IV da CF. 
No que tange ao conceito de veículo automotor, objeto do presente estudo, este será detalhadamente descrito ao longo do texto, para que se possa delimitar o campo de abrangência desta expressão.

De forma introdutória, vale dizer que veículo "é o instrumento ou aparelho que, dotado de certos requisitos, serve ao transporte de coisas ou de pessoas, de um para outro lugar" (SILVA apud MAMEDE, 2002, p. 52).

Entretanto, para o IPVA, no universo de veículos, somente a propriedade sobre os veículos automotores é passível de tributação. Nesse contexto é que surgem as divergências doutrinárias e legislativas, uma vez que, veículos automotores são aqueles dotados de motor, cujo mecanismo possibilita a autolocomoção.

Assinala Mamede que o motor é o mecanismo que gera movimento e pode transmitir, provocar movimento.

Esse movimento é gerado por formas diversas, por exemplo, por campos magnéticos nos motores elétricos, ou pela combustão de substâncias inflamáveis (...). Não há uma definição que dê uma conformação obrigatória ao motor que movimenta o veículo, apenas a exigência de que o movimento seja produzido por uma motor, mesmo que de forma auxiliar. (M EM EDE, 2002, p. 53).

Assim, as definições de veículo automotor terrestre, aeronaves e embarcações acabam contendo pontos em comum, uma vez que todos contam com um movimento intrínseco a sua estrutura, se automovimentam através de um motor, para transporte de pessoas ou coisas. Desta forma instala-se o conflito sobre o alcance do conceito de veículo automotor a ensejar tal exação tributária.

\section{Divergências em relação ao critério material do ipva - limites da expressão "veículo automotor"}

Como já visto, o IPVA tem como hipótese de incidência prevista no art.155, III da Constituição Federal, a "propriedade de veículo automotor".

A autorização constitucional conferida para a incidência do IPVA demonstra que não é qualquer veículo que estende aos seus proprietários a obrigação tributária, sendo apenas a propriedade de veículos automotores que possibilita a incidência.

Veículos automotores se distinguem dos demais, devido a sua causa de 


\title{
Limites da expressão "veículos automotores" para fins de incidência do IPVA: as embarcações e aeronaves
}

movimentação, que diferentemente de forças externas, tais como, o vento, a água ou a força animal, contam com um movimento intrínseco a sua estrutura, se automovimentando através de um motor. Assim, ficam excluídos da tributação da Fazendo Pública Estadual, por exemplo, carroças e barcos a remo ou a vela, e incluídos todos os veículos que dependem de um motor para se movimentarem, tais como, carros, ônibus, furgões, vans, carretas, caminhonetes, caminhões, ciclomotores (motocicleta, motoneta, triciclo, quadriciclo), não interessando para fins de incidência, a fabricação artesanal ou regular do veículo ou a finalidade do veículo (M AM EDE, 2002, p. 53).

Porém, no campo da abrangência do critério material da hipótese tributária do IPVA, há grande controvérsia a respeito das embarcações e aeronaves ser consideradas veículos automotores e conseqüentemente sujeitarem seus proprietários ao imposto.

0 anexo I do Código de Trânsito Brasileiro (Lei no 9.503/97), traz o conceito de veículo automotor, dizendo que:

\begin{abstract}
Veículo Automotor é todo veículo a motor de propulsão que circule por seus próprios meios, e que serve normalmente para o transporte viário de pessoas e coisas, ou para a tração viária de veículos utilizados para o transporte de pessoas e coisas. 0 termo compreende os veículos conectados a uma linha elétrica e que não circulam sobre trilhos ônibus elétrico.
\end{abstract}

O conceito de aeronave vem descrito no caput, do art. 106, do Código Brasileiro de Aeronáutica (Lei no 7.565/86) que afirma: "Considera-se aeronave todo aparelho manobrável em vôo, que possa sustentar-se e circular no espaço aéreo, mediante reações aerodinâmicas, apto a transportar pessoas ou coisas".

De outro lado, o conceito legal do termo embarcação, conforme disposição do artigo 10 do Regulamento de Tráfego M arítimo (Decreto o 87.648/82), diz que embarcação, "significa qualquer construção, capaz de transportar pessoas ou coisas, suscetível de se locomover na água por meios próprios ou não".

Segundo algumas posições doutrinárias, tal como a de Ricardo Alvarenga, apresentada por Gladston Mamede, embarcações e aeronaves não estariam inclusas no conceito de veículo automotor por se tratarem de coisas distintas, com características peculiares, não podendo ser equiparadas para incidência do IPVA, pois, embora possuam alguns pontos em comum já que ambas têm motor de propulsão, circulam por seus próprios 
meios e transportam pessoas ou coisas, o legislador ao conceituar veículo automotor na regra-matriz de incidência do IPVA, não as quis equiparar a esse último para fins tributários, pois teria dado conotação terrestre ao empregar o termo "transporte viário" quando da conceituação de veículo automotor (ALVARENGA Apud M AM EDE 2002, p. 54).

Já para outros doutrinadores, como Gladston Mamede, embarcações e aeronaves estariam abrangidas pelo conceito eis que ainda que se movimentem pelo ar ou água, são veículos de transporte e possuem um motor, exibindo dessa forma, a qualidade para sofrerem incidência tributária (2002, p. 54).

\section{Argumentos favoráveis à incidência}

Dentre os argumentos favoráveis a incidência do IPVA sobre embarcações e aeronaves, destaca-se 0 de Gladston Mamede que acredita que a expressão veículo automotor é ampla o suficiente para abranger embarcações e aeronaves, tendo o dispositivo constitucional a aptidão para abranger a propriedade de qualquer veículo que tenha propulsão própria e sirva ao transporte de pessoas e coisas (2002, p. 53).

\footnotetext{
Defensor dessa corrente, o Ministro do Supremo Tribunal Federal, Marco Aurélio, em voto divergente em Recurso Extraordinário (RE 255111/SP), diz que:

Não se pode introduzir no dispositivo constitucional limitação que nele não se contém. A incidência abrange a propriedade de todo e qualquer veículo, ou seja, que tenha propulsão própria e que sirva ao transporte de pessoas e coisas, tais como, embarcações, aeronaves, automóveis de passeio, caminhoneta de uso misto, motocicletas, ciclomotores e automóveis de corrida.

E também no Recurso Extraordinário (379572/ RJ), defende a incidência afirmando que:

0 tributo apenas requer 0 elo entre 0 veículo, o gênero, e 0 proprietário, 0 detentor da titularidade, ou seja, a propriedade, como está no texto, desse mesmo veículo automotor, pouco importando a natureza.
}

Um outro argumento muito utilizado por aqueles que defendem a incidência do imposto é de que em virtude da inexistência de uma lei de caráter nacional, que unifique tais conceitos, incumbiria às legislações estaduais definir o conceito de veículo automotor sujeito à incidência do IPVA. Assim, amparados no art. 24, § 3ㅇda Constituição Federal que diz que “inexistindo lei federal sobre normas gerais, os Estados exercerão a competência legislativa plena, para atender as suas peculiaridades", e ainda, no artigo 34, § 3ㅇ do Ato das Disposições Constitucionais Transitórias, que diz que: "promulgada a Constituição, a União, 


\section{Limites da expressão "veículos automotores" para fins de incidência do IPVA: as embarcações e aeronaves}

os Estados, o Distrito Federal e os M unicípios poderão editar as leis necessárias à aplicação do sistema tributário nacional nela previsto", os estados estariam plenamente legitimados a instituir o imposto sobre embarcações e aeronaves. (RESENDE, 2008).

Existe ainda, um último argumento favorável à incidência, qual seja a de que o imposto é sucessor da antiga TRU (Taxa Rodoviária Única), sendo essa específica para veículos terrestres, pois tinha como vinculação a manutenção e melhoria das estradas, e, dessa forma, por não ter o legislador restringido o critério material do novo imposto (IPVA), apenas quanto a veículos automotores terrestres, defende-se que não teria sido essa a sua intenção.

Segue abaixo um trecho do voto do ministro Francisco Rezek acerca da incidência do imposto:

Os conhecedores do modo nacional de se produzirem textos constitucionais hão de perguntar-se sempre se o constituinte, caso quisesse que o legatário da velha e conhecida Taxa Rodoviária Única se tornasse um imposto capaz de alcançar aviões e navios, teria se omitido de fazer referência a embarcações e aeronaves. É claro: se se fizer a análise etimológica da expressão veículos automotores é sempre possível concluir que se pode enquadrar no conceito de veículo automotor o navio e a aeronave. Pode ser enquadrada também qualquer criatura do reino animal, veículo que é porque capaz de transportar coisas e automotor porque depende de qualquer tração externa de sua própria estrutura física. Dos animais mais lentos, na espécie dos moluscos, aos mais velozes; dos mais robustos, como a formiga, que carrega vinte e cinco vezes o seu próprio peso, aos mais frágeis, todos nos incluiríamos no conceito de veículo automotor se ele devesse ser compreendido semanticamente. Já se viu que não é isso. Inúmeras discussões em nosso plenário sobre o que é circulação de mercadorias nos fazem ver que a concepção literal dessa fórmula nos conduziria ao ridículo.

Contudo, o argumento mais forte e pautado na tão repudiada interpretação histórica, e inclusive apontado diversas vezes nas decisões sobre o tema do STF, é de que o IPVA é sucessor da antiga TRU, sendo que esta era específica para veículos terrestres, não devendo o imposto, portanto, ser diferente (FÉLIX; GARCIA, 2007).

\section{Argumentos contrários à incidência}

Da invasão dos estados em matéria de competência exclusiva da união

A maioria doutrinária que defende a não abrangência de embarcações e aeronaves na hipótese de incidência do IPVA, argumentam que a lei não pode ensejar dúvidas sobre o 
critério material de qualquer tributo, devendo este ser certo, específico e bem definido, em nome da segurança jurídica, legalidade e tipicidade tributária (SILVA, 2004).

Além disso, para estes mesmos defensores, tendo 0 art. 22, I da CF, disposto sobre a competência exclusiva de a União legislar sobre direito aeronáutico e direito marítimo, estar- se-ia o estado que estendesse em sua legislação o conceito de veículo automotor, usurpando de um competência federal, como se vê da leitura do referido artigo: "Compete privativamente a União legislar sobre: I - direito civil, comercial, penal, processual, eleitoral, agrário, marítimo, aeronáutico, espacial e do trabalho".

Ademais, esses mesmos defensores argumentam no sentido de que as aeronaves e as embarcações são registradas de forma única prevista na legislação federal (RAB e Tribunal Marítimo), e por conta disso, somente a União poderia tributar sobre a propriedade daqueles veículos.

Todavia, essa não exerce tributação sobre a propriedade das aeronaves e embarcações, uma vez que seus proprietários já pagam pelas taxas de utilização dos aeroportos e portos, assim como pela infra-estrutura disponibilizada, não podem os Estados instituírem o IPVA.

Por conseguinte, segundo essa tese, os Estados ao instituírem a cobrança de IPVA sobre aeronaves e embarcações, estaria invadindo a área de competência exclusiva da União.

Da vedação da aplicação da analogia para a cobrança do IPVA

Como se pode constatar, por serem as definições de aeronaves, embarcações e veículos automotores distintas em sua natureza, somente através do emprego de interpretação analógica da norma tributária, que seria possível à instituição do IPVA sobre aeronaves e embarcações.

Entretanto, $0 \S 1^{\circ}$, do art. 108, do CTN, veda expressamente a cobrança de tributo sobre hipótese de incidência não expressa prevista em lei, face ao princípio da legalidade tributária. 


\section{Limites da expressão "veículos automotores" para fins de incidência do IPVA: as embarcações e aeronaves}

Art.108: Na ausência de disposição expressa, a autoridade competente para aplicar a legislação tributária utilizada sucessivamente, na ordem indicada: I - analogia; II os princípios gerais de direito tributário; III - os princípios gerais de direito público; IV - a equidade.

§10: 0 emprego da analogia não poderá resultar na exigência de tributo não previsto em lei.

O doutrinador César Augustus M azzoni, citando Kiyoshi Harada sobre a analogia em matéria tributária, ensina que a embora a analogia figure em primeiro lugar, não quer dizer que ela tenha maior relevância ou aplicação no campo tributário, pois, por força do princípio da legalidade tributária, ela só tem aplicação na área do direito processual, não podendo ter aplicação no âmbito do direito material, ou seja, em relação aos elementos constitutivos da obrigação tributária como prevê o parágrafo primeiro (HARADA Apud M AZZONI 2005).

Da mesma forma, diz Hugo de Brito Machado que a analogia vem a ser um mecanismo de integração, e não de interpretação, sendo que o aplicador da lei apenas recorrerá a esse meio na ausência de disposição expressa e específica, não podendo o emprego da analogia resultar na exigência de tributo não previsto em lei (MACHADO, 2002, p. 49)

Logo, como os conceitos de aeronaves, embarcações e veículos automotores são distintos entre si, e o IPVA refere-se exclusivamente a veículos automotores, com denotação terrestre, não seria possível utilizar a analogia para estender a cobrança do IPVA sobre aeronaves e embarcações, por expressa vedação legal.

\section{Ausência de registro estadual e municipal}

Ainda, pesa em favor dos que defendem a não incidência do IPVA sobre embarcações e aeronaves o fato destes meios de transporte não se vincularem a nenhum registro junto ao ente da repartição constitucional da receita do IPVA, que é o município, uma vez que o banco de dados de embarcações e aeronaves é de registro nacional, especificamente no Tribunal Marítimo (órgão executivo) e no RAB (Registro Aeronáutico Brasileiro), pertencente à ANAC, não existindo vínculo do registro nem mesmo perante aos Estados (FÉLIX; GARCIA, 2007).

Sob essa conjectura, mesmo os Estados que adotaram em suas legislações estaduais o conceito amplo de veículos automotores, incluindo embarcações e aeronaves tais como, 0 
estado do Rio de Janeiro e do Espírito Santo, não conseguem implementar a cobrança, eis que o banco de dados destes veículos pertence a Fazenda Federal.

$\mathrm{Na}$ verdade esse argumento constitui-se falho à medida que existem alguns mecanismos previstos em algumas legislações estaduais sobre a adoção de mecanismos de controle dos registros desses veículos para a cobrança do IPVA. Como exemplo, tem-se o Decreto estadual № 26.428, de 29 de dezembro de 2006, do Amazonas.

Esse decreto regulamenta o IPVA no Estado e altera os mecanismos de controle e fiscalização do imposto, exigindo em seu art.27, que todo proprietário de veículo automotor que seja domiciliado no Estado se inscreva em um Cadastro de Contribuintes do IPVA, de origem estadual, apenas dispensando essa inscrição, caso haja troca de informações oriundas de convênios firmados entre a Fazenda estadual e o órgão federal, em que se possa identificar o veículo e o proprietário.

\begin{abstract}
Art. 27. Desde que o proprietário de veículo automotor seja domiciliado ou residente neste Estado fica obrigado a inscrevê-lo no Cadastro de Contribuintes do IPVA.

§ 10 Fica dispensado da inscrição referida no caput deste artigo o proprietário de veículo automotor terrestre que tenha realizado o registro e o licenciamento do veículo no Departamento Estadual de Trânsito - DETRAN, conforme a legislação pertinente.

§ 40 Aplica-se 0 disposto no $\$ 10$ deste artigo no caso de aeronaves ou embarcações, quando a Secretaria de Estado de Fazenda, mediante convênio com os órgãos federais responsáveis pelo registro desses veículos, possuir acesso às informações cadastrais necessárias à cobrança do imposto.
\end{abstract}

\title{
Jurisprudências
}

O STF, sempre em decisões por maioria de votos, em que saem vencidos os Ministros Marco Aurélio e Joaquim Barbosa, defensores da cobrança, em Recursos Extraordinários, decidiu reiteradas vezes acerca da não incidência do IPVA sobre embarcações e aeronaves com base nos argumentos já expostos.

A exemplo têm-se:

EMENTA:

"IPVA - Imposto sobre Propriedade de Veículos Automotores (CF, art. 155, III; CF 69 , art. 23 , III e $\S 13$, cf. EC 27/85): campo de incidência que não inclui embarcações e aeronaves. Recurso extraordinário conhecido e provido por maioria de votos".

(RE 255111/SP - SÃO PAULO- RECURSO EXTRAORDINÁRIO, Relator(a): Min. M ARCO 


\section{Limites da expressão "veículos automotores" para fins de incidência do IPVA: as embarcações e aeronaves}

AURÉLIO, Relator(a) p/ Acórdão: Min. SEPÚLVEDA PERTENCE. Julgamento: 29/05/2002, Órgão Julgador: Tribunal Pleno.)

\section{EMENTA:}

"Recurso Extraordinário. Tributário. Não incide Imposto de Propriedade de Veículos Automotores (IPVA) sobre embarcações (Art. 155, III, CF/88 e Art. 23, III e § 13, CF/67 conforme EC 01/69 e EC 27/85). Precedentes. Recurso extraordinário conhecido e provido por maioria de votos".

(RE 379572/RJ - RIO DE JANEIRO- RECURSO EXTRAORDINÁRIO, Relator(a): Min. GILM AR MENDES, Julgamento: 11/04/2007, Órgão Julgador: Tribunal Pleno)

\section{EMENTA:}

IPVA - Imposto sobre Propriedade de Veículos Automotores (CF, art. 155, III; CF 69, art. 23, III e § 13, cf. EC 27/85): campo de incidência que não inclui embarcações e aeronaves. Recurso extraordinário conhecido e provido por maioria de votos".

(RE 134509 / AM - AMAZONAS - RECURSO EXTRAORDINÁRIO, Relator(a): Min. MARCO AURÉLIO, Relator(a) p/ Acórdão: Min. SEPÚLVEDA PERTENCE, Julgamento: 29/05/2002, Órgão Julgador: Tribunal Pleno.)

E também o Tribunal de Justiça do Estado do Paraná, com base nos mesmos argumentos do STF, entendeu pela não incidência do IPVA sobre a propriedade de aeronaves.

EM ENTA: APELAÇÃO CÍVEL E REEXAME NECESSÁRIO - MANDADO DE SEGURANÇA IPVA - INADMISSIBILIDADE DE INCIDÊNCIA SOBRE AERONAVE - VEÍCULO AUTOMOTOR - CONCEITO QUE NÃO ABRANGE O ESTABELECIDO NO CÓDIGO BRASILEIRO DE AERONÁUTICA - PRECEDENTE DO SUPREM O TRIBUNAL FEDERAL ANALOGIA VEDADA EM RAZÃO DO DISPOSTO NO ARTIGO 108, § 1ㅇ, DO CÓDIGO TRIBUTÁRIO NACIONAL - RECURSO NÃO PROVIDO - SENTENÇA MANTIDA EM REEXAM E NECESSÁRIO. "IPVA Imposto sobre Propriedade de Veículos Automotores (CF, art. 155, III, CF 69, art. 23, III e § 13, cf. EC 27/85): campo de incidência que não inclui embarcações e aeronaves." (STF - Recurso Extraordinário no 255.111-SP Tribunal Pleno - Relator Ministro Sepúlveda Pertence).

(TJPR - Acórdão no.26111 - PR, Processo no.0180046-2, Apelação Cível e Reexame Necessário, Comarca: Curitiba, Julgamento: 07/02/2006, Decisão: Unânime, Órgão Julgador: 2aㅡ Câmara Cível.)

\section{Veículos utilitários}

Ainda no que tange aos limites da expressão "veículo automotor", em relação aos chamados veículos utilitários, Gladston Mamede adverte que quando os Estados exercem a competência tributária sobre eles, estar-se-ia diante de uma incompatibilidade entre a idéia central da autorização trazida pela constituição para incidência do IPVA sobre "veículo automotor" e determinados tipos de maquinário que possuem na autolocomoção apenas um elemento acessório de sua principal razão de ser (2002, p. 56).

Segundo Mamede, os veículos utilitários: 


\begin{abstract}
Não são propriamente veículos motorizados com a finalidade de locomoção e/ ou transporte, mas máquinas utilitárias que dispõem de mecanismos de autolocomoção como forma de otimizar os resultados de sua atuação. Os exemplos são múltiplos: retroescavadeira, guindaste, rolo compressor, pá carregadeira, escavadeira, empilhadeira, no âmbito agrícola, encontraremos colheitadeira, ceifadeira, plantadeira e outras (MAM EDE, 2002,p. 56).
\end{abstract}

Segundo ainda o mesmo autor, pretender incluir os veículos utilitários no conceito de veículo automotor seria negar o principal conteúdo da mensagem normativa contida no texto constitucional, eis que ocorreria a valorização de um elemento acidental, que é o fato de eles serem veículos que se autolocomovem por meio de um motor e desprezo de um elemento essencial desses, que vem a ser a otimização de produção, e não o transporte de pessoas ou coisas (M AM EDE, 2002, p. 56).

Seguindo esse entendimento, alguns Estados, reconhecendo essa incompatibilidade entre os veículos utilitários e veículos automotores trazidos pela Constituição, concederam isenção do IPVA, atingindo o critério material da norma abstrata e geral que introduz a hipótese tributária, impedindo a incidência do imposto sobre determinados veículos proibidos de trafegar em vias públicas, tais como os de peso que exceda aos limites impostos pelo CONTRAN, em que se enquadram os utilitários.

A exemplo têm-se a lei estadual $n-14.260 / 2003$ do Paraná, que diz em seu art.14, inciso I: "Estão isentos do pagamento do IPVA os veículos; I- que, em razão do tipo, a legislação específica proíba o tráfego em vias públicas".

\title{
Solução da controvérsia através de lei complementar
}

Diante da inexistência de uma lei complementar que regulamente nacionalmente 0 IPVA, cada Estado edita sua própria legislação sobre o referido imposto. Com isso, são muitas as questões conflitantes das várias legislações estaduais do IPVA existentes no país. Por isso, acredita-se que a edição de uma lei complementar dotada de normas nacionais a respeito de pontos controvertidos, contribuiria para a resolução de tais problemas, permitindo a solução de questões que geram divergência na doutrina e na jurisprudência, como por exemplo, a abrangência ou não das aeronaves e embarcações no conceito de veículo automotor, bem como outras controvérsias quanto a expressão "veículo automotor", como a possibilidade de incidência do IPVA sobre veículos utilitários. 


\section{Limites da expressão "veículos automotores" para fins de incidência do IPVA: as embarcações e aeronaves}

\section{Conclusão}

0 estudo dos limites da expressão do critério material da hipótese de incidência tributária do IPVA, "veículo automotor", quanto a sua abrangência sobre as embarcações e as aeronaves, teve por base, principalmente a apresentação imparcial de teses doutrinárias e jurisprudenciais favoráveis e contrárias à incidência do imposto sobre esses veículos.

Segundo a doutrina que defende a cobrança do imposto pelos Estados, destaca-se a de Gladston Mamede (2002) que acredita que o dispositivo constitucional contido no art.155, III, tem a aptidão para abranger a propriedade de qualquer veículo que tenha propulsão própria e sirva ao transporte de pessoas e coisas, estando assim incluídas, as embarcações e aeronaves.

De um outro lado, alguns doutrinadores como Ricardo Alvarenga, baseando-se no conceito apresentado pela legislação de trânsito acerca de veículo automotor, entendem que aqueles veículos, por mais que possuam características em comum ao automotor, não detem a qualidade "terrestre", que fora desejada pelo legislador ao empregar o termo "transporte viário" quando da conceituação de veículo automotor, estando assim, fora da competência tributária dos Estados.

Verificou-se, contudo, que as teses contrárias à incidência ganham maior repercussão perante os Estados, uma vez que, como pode se observar pelos julgados colacionados, o Supremo Tribunal Federal firmou precedente ao entender pela não incidência do IPVA sobre embarcações e aeronaves como base nos argumentos trazidos a análise.

Por fim, conclui o presente artigo pela observância da legislação estadual acerca da incidência ou não do IPVA sobre esses veículos, diante da conceituação dada para veículo automotor por cada Estado, apresentando como solução a controvérsia da incidência, a criação de uma lei complementar, que veicule um conceito de abrangência nacional sobre veículo automotor. 


\section{Referências}

AM AZONAS. Decreto estadual no 26.428, de 29 de dezembro de 2006. Aprova 0 Regulamento do Imposto sobre a Propriedade de Veículos Automotores (RIPVA). Diário Oficial do Estado, M anaus, AM, 29 de dezembro de 2006.

BRASIL. Constituição (1988). Constituição da República Federativa do Brasil. Brasília, DF, 1988.

. Lei no .9.503, de 23 de setembro de 1997. Institui o Código de Trânsito Brasileiro. Diário Oficial da União, Brasília, DF, 24 de setembro de 1997.

. Lei no.7.565, de 19 de dezembro de 1986. Código Brasileiro de Aeronáutica. Diário Oficial da União, Brasília, DF, 20 de dezembro de 1997.

FÉLIX, Giovanna Araújo; GARCIA, M aria Luiza. A extensão da expressão veículo automotor para fins de incidência do IPVA. Disponível em:

http://www2.uel.br/revistas/direitopub/pdfs/VOLUME_3/num_1/Maria\%20Luiza\%20Garcia \%5B1\%5D.pdf. Acesso em: 28/10/2008.

M ACHADO, Hugo de Brito. Curso de Direito Tributário. 13 ed. revista, atualizada e ampliada. São Paulo: Editora M alheiros, 1998.

M AM EDE, Gladston. IPVA: Imposto sobre a propriedade de veículos automotores. colaboração Eduarda Cotta Mamede. São Paulo: Editora Revista dos Tribunais, 2002.

M ARTINS, Rogério L. Vidal Dangra da Silva. Curso de Direito Tributário. Coordenação Ives Gandra Martins. São Paulo: Saraiva, 2007

M AZZONI, César Augustus. A ilegalidade da incidência de IPVA sobre aeronaves e embarcações. Disponível em:

$\varangle$ ttp://www.escritorioonline.com/webnews/noticia.php?id_noticia $=5890 \&>$. Acesso em: 30/10/2008.

PARANÁ. Lei no -14.260 , de 22 de dezembro de 2003. Estabelece normas sobre o tratamento tributário pertinente ao imposto sobre a propriedade de veículos automotores - IPVA. Diário Oficial do Estado, Curitiba, PR, 23 de dezembro de 2003.

RESENDE, Janaína da Silva. Incidência do IPVA sobre embarcações e aeronaves. Disponível em: বttp://www.lfg.com.br>. Acesso em: 26/10/ 2008.

SILVA, Eduardo Corrêa da. A não incidência do imposto sobre propriedade de veículos automotores (IPVA) sobre embarcações e aeronaves. Disponível em: বhttp://jus2.uol.com.br/doutrina/texto.asp?id=6312>. Acesso em: 28/10/2008. 